\title{
DELINEAMENTO EXPERIMENTAL E TAMANHO DE AMOSTRA PARA ALFACE CULTIVADA EM HIDROPONIA
}

\author{
EXPERIMENTAL DESIGN AND SAMPLE SIZE FOR HYDROPONIC \\ LETTUCE CROP
}

\author{
Valéria Schimitz Marodim ${ }^{1}$ Lindolfo Storck ${ }^{2}$ Sidinei José Lopes ${ }^{3}$ \\ Osmar Souza dos Santos ${ }^{4}$ Denise Schimidt ${ }^{1}$
}

RESUMO

\begin{abstract}
Este estudo visa a estabelecer o delineamento experimental e o tamanho de amostra para a cultura da alface (Lactuca sativa) em hidroponia, pelo sistema NFT (Nutrient film technique). O experimento foi conduzido no Laboratório de Cultivos Sem Solo/Hidroponia, no Departamento de Fitotecnia da Universidade Federal de Santa Maria e baseou-se em dados de massa de plantas. Os resultados obtidos mostraram que, usando estrutura de cultivo de alface em hidroponia sobre bancadas de fibrocimento com seis canais, o delineamento experimental adequado é blocos ao acaso se a unidade experimental for constituída de faixas transversais aos canais das bancadas, $e$ deve ser inteiramente casualizado se a bancada for a unidade experimental; para a variável massa de plantas, o tamanho da amostra é de 40 plantas para uma semi-amplitude do intervalo de confiança em percentagem da média (d) igual a $5 \%$ e de 7 plantas para um digual a $20 \%$.
\end{abstract}

Palavras-chave: amostragem, Lactuca sativa, variância, nutrientes.

\section{SUMMARY}

This study was carried out to establish the experimental design and sample size for hydroponic lettuce (Lactuca sativa) crop under nutrient film technique. The experiment was conducted in the Laboratory of Hydroponic Crops of the Horticulture Department of the Federal University of Santa Maria. The evaluated traits were plant weight. Under hydroponic conditions on concrete bench with six ducts, the most indicated experimental design for lettuce is randomised blocks for duct transversal plots or completely randomised for bench plot. The sample size for plant weight should be 40 and 7 plants, respectively, for a confidence interval of mean percentage (d) equal to $5 \%$ and $20 \%$.

Key words: sampling, Lactuca sativa, variance, nutrients

\section{INTRODUÇÃO}

Hidroponia é uma técnica na qual se utilizam água e sais minerais para o desenvolvimento de plantas em ambientes protegidos. Esse método de cultivo foi empregado na antiguidade, mas somente há alguns anos vem sendo utilizado, principalmente, no cultivo de hortaliças e flores (PENNINGSFELD \& KURZMANN, 1983; PELLINCER et al., 1995).

A determinação do delineamento experimental e do tamanho da amostra é importante em todos os experimentos científicos, podendo influenciar na precisão dos ensaios. Se a amostra for subdimensionada, os resultados não são confiáveis, e se for grande demais em relação ao tamanho ideal ocorre desperdício de tempo e recursos financeiros.

Existem vários estudos determinando o tamanho ideal de amostra para as mais diversas culturas e métodos. Para hortaliças, pode-se citar os trabalhos de LOPES $\boldsymbol{e}$ al. (1998) e PEIRETTI $\boldsymbol{e}$ t al. (1990). A maioria desses trabalhos foi realizada a campo ou em ambientes protegidos com culturas no

\footnotetext{
${ }^{1}$ Engenheiro Agrônomo, Aluna do Programa de Pós-graduação em Agronomia, Universidade Federal de Santa Maria (UFSM).

${ }^{2}$ Engenheiro Agrônomo, Doutor, Professor Titular do Departamento de Fitotecnia. Centro de Ciências Rurais (CCR)/UFSM. 97105-900

Santa Maria, RS. Bolsista do CNPq. E-mail: storck@ccr.ufsm.br. Autor para correspondência.

${ }^{3}$ Engenheiro Agrônomo, Mestre, Professor Assistente do Departamento de Fitotecnia. CCR/UFSM.

${ }^{4}$ Engenheiro Agrônomo, Doutor, Professor Aposentado, CCR/UFSM. Pesquisador do CNPq.
} 
solo. MIRANDA FILHO (1987) cita que o principal determinante da heterogeneidade entre parcelas a campo é a variabilidade do solo; porém, não se tem informação da variabilidade entre plantas, quando estas estão em cultivo sem solo. Para a determinação do tamanho ideal de parcelas, tem-se lançado mão de diversos métodos e, entre eles, pode-se citar: método de Cochran, método da máxima curvatura do coeficiente de variação, método de H. Fairfield Smith, método da informação relativa, método de W. H. Hatheway, entre outros (ZANON et al., 1997).

Devido à inexistência de dados sobre a variabilidade entre plantas em cultivo sem solo, este experimento tem como objetivo determinar o tamanho ideal de amostra e o delineamento experimental para a cultura da alface, cultivar Elba, utilizando-se a técnica da hidroponia.

\section{MATERIAL E MÉTODOS}

O experimento com a cultura da alface, cultivar Elba, foi conduzido em ambiente protegido sobre bancadas (mesas) hidropônicas no Departamento de Fitotecnia da Universidade Federal de Santa Maria. O ambiente protegido constava de uma estufa de plástico com $250 \mathrm{~m}^{2}$, sendo as bancadas constituídas de chapas de fibrocimento com seis canais impermeabilizados com neutrol, colocados sobre cavaletes com desnível de $1 \%$ para o escoamento da solução nutritiva. Em cada canal, foram colocadas 14 plantas de alface. A solução nutritiva era fornecida por 15 minutos, com intervalos de 15 minutos, ajustados através de temporizador.

No experimento, com seis bancadas, executado nos meses de março a maio de 1998, foi utilizada a solução nutritiva proposta por CASTELLANE \& ARAÚJO (1994), com a concentração de $50 \%$ na produção das mudas e $100 \%$ na fase de produção. As plantas foram sustentadas por brita, isopor e lona plástica dupla-face, duas bancadas para cada material.

A variável avaliada foi a massa obtida de cada planta nos seis canais, em todas as bancadas.

A análise estatística constou de análise da variância, regressão, teste de homogeneidade de variâncias entre canais e entre bancadas, estimativas de médias, coeficiente de variação e tamanho ideal de amostra para uma semi-amplitude do intervalo de confiança (d) igual a 5, 10 e $20 \%$ da média, com um nível de erro igual a $5 \%$.

O método utilizado para a determinação do tamanho da amostra (n) foi o proposto por PÉLLICO NETTO \& BRENA (1993):

$$
\mathrm{n}=\frac{\mathrm{Nt}^{2}(\mathrm{CV} \%)^{2}}{\mathrm{~N}(\mathrm{~d})^{2}+\mathrm{t}^{2}(\mathrm{CV} \%)^{2}}
$$

onde $\mathrm{n}$ é o tamanho da amostra, $\mathrm{t}$ é o valor da tabela de $\mathrm{t}$, tendo sido usado $\alpha=0,05$; $\mathrm{N}$ é o número total de plantas na unidade amostral; CV\% é o coeficiente de variação em percentagem da média e d é a semiamplitude do intervalo de confiança expresso em percentagem da média. O teste de Bartlett (STEEL \& TORRIE, 1960) foi utilizado para determinar a homogeneidade das variâncias entre as bancadas.

\section{RESULTADOS E DISCUSSÃO}

O resultado da análise de regressão linear simples da massa das plantas (variável dependente) com a posição da planta dentro dos canais (valor 1 para a planta na parte mais alta até valor 14 para a planta na parte mais baixa do canal - variável independente) mostrou que não há efeito da declividade e/ou do sentido da entrada e saída da água no canal sobre a massa das plantas. Em quatro das seis bancadas (as duas de brita e as duas de plástico - tabela 1), a diferença entre as médias dos seis canais é significativa pelo teste de F, tomando as 14 plantas como repetições. No entanto, não houve diferença entre as médias das bancadas, de forma que o canal não pode ser usado como unidade experimental em experimentação com alface em hidroponia. Caso seja necessário usar divisões nas bancadas para casualizar diferentes tratamentos, as unidades experimentais devem ser tomadas, preferencialmente, com divisões transversais aos canais, de tal forma que cada unidade alcance os seis canais. Assim, o delineamento experimental pode ser em blocos ao acaso (bloco igual a subdivisões transversais aos canais da bancada) se a unidade experimental for divisões das bancadas, ou delineamento inteiramente casualizado se a unidade experimental for a bancada inteira.

Comparando-se os coeficientes de variação das diferentes bancadas de diferentes materiais de sustentação (Tabela 1), pode-se perceber que estes diferem pouco para a variável massa fresca de plantas. Para os três materiais utilizados para sustentação das plantas, as variâncias da massa das plantas não foram heterogêneas na totalidade das bancadas (Tabela 1), nem entre as bancadas.

Os tamanhos de amostra para uma semiamplitude do intervalo de confiança expresso em percentagem da média (d), igual a 5, 10 e $20 \%$, com $5 \%$ de probabilidade de erro (Tabela 2 ), considerando uma população finita igual a 84 plantas por bancada, estão quantificados em função do valor d. Existe uma boa repetibilidade entre as bancadas e 
Tabela 1 - Média (g/planta), variância $\left(\mathrm{s}^{2}\right)$ e coeficiente de variação (CV\%) estimados da massa fresca das 14 plantas de alface por canal, média e variância por bancada e no geral. Santa Maria, 1998.

\begin{tabular}{|c|c|c|c|c|c|}
\hline Suporte & Bancada & Canal & Média & $S^{2}$ & $\mathrm{CV} \%$ \\
\hline \multirow[t]{7}{*}{ Brita } & 1 & 1 & 203,7 & 2219,5 & \\
\hline & & 2 & 188,2 & 1283,5 & \\
\hline & & 3 & 207,2 & 1505,1 & \\
\hline & & 4 & 161,2 & 2458,9 & \\
\hline & & 5 & 169,5 & 790,4 & \\
\hline & & 6 & 222,9 & 2508,7 & \\
\hline & Média & & $192,1 *$ & $1794,4^{\text {ns2 }}$ & 22,05 \\
\hline \multirow[t]{7}{*}{ Brita } & 2 & 1 & 223,3 & 1649,6 & \\
\hline & & 2 & 180,8 & 1734,8 & \\
\hline & & 3 & 185,2 & 1876,9 & \\
\hline & & 4 & 161,5 & 911,5 & \\
\hline & & 5 & 196,4 & 762,8 & \\
\hline & & 6 & 214,9 & 1526,8 & \\
\hline & Média & & $193,7 *$ & $1410,4^{\text {ns2 }}$ & 19,39 \\
\hline \multirow{7}{*}{ Isopor } & 1 & 1 & 191,5 & 2941,3 & \\
\hline & & 2 & 173,5 & 836,1 & \\
\hline & & 3 & 183,5 & 2867,9 & \\
\hline & & 4 & 188,3 & 3054,4 & \\
\hline & & 5 & 179,5 & 1202,0 & \\
\hline & & 6 & 183,2 & 2087,5 & \\
\hline & Média & & $183,2^{\mathrm{ns} 1}$ & $2164,9^{\text {ns2 }}$ & 25,39 \\
\hline \multirow[t]{7}{*}{ Isopor } & 2 & 1 & 182,5 & 1633,3 & \\
\hline & & 2 & 187,6 & 2804,3 & \\
\hline & & 3 & 197,4 & 1382,9 & \\
\hline & & 4 & 187,3 & 1395,0 & \\
\hline & & 5 & 191,3 & 1368,4 & \\
\hline & & 6 & 179,4 & 1186,6 & \\
\hline & Média & & $187,6^{\mathrm{ns} 1}$ & $1628,4^{\mathrm{ns} 2}$ & 21,51 \\
\hline \multirow[t]{7}{*}{ Plástico } & 1 & 1 & 205,5 & 2737,7 & \\
\hline & & 2 & 161,3 & 1339,6 & \\
\hline & & 3 & 189,1 & 1239,8 & \\
\hline & & 4 & 160,9 & 1204,0 & \\
\hline & & 5 & 181,6 & 1193,7 & \\
\hline & & 6 & 193,3 & 1784,5 & \\
\hline & Média & & $181,9 *$ & $1583,2^{\text {ns2 }}$ & 21,87 \\
\hline \multirow[t]{8}{*}{ Plástico } & 2 & 1 & 213,9 & 2664,5 & \\
\hline & & 2 & 169,7 & 969,2 & \\
\hline & & 3 & 193,5 & 1561,9 & \\
\hline & & 4 & 181,8 & 3242,7 & \\
\hline & & 5 & 186,1 & 1210,2 & \\
\hline & & 6 & 216,3 & 1024,9 & \\
\hline & Média & & $193,5 *$ & $1788,7^{\text {ns2 }}$ & 21,88 \\
\hline & Média geral & & $188,7^{\mathrm{ns} 1}$ & $1728,3^{\text {ns2 }}$ & - \\
\hline
\end{tabular}

* Diferença entre médias de canais e entre bancadas significativas pelo teste de $\mathrm{F}$ em nível de $5 \%$ de probabilidade de erro;

ns1 diferença entre médias de canais e entre bancadas não significativas;

ns2 Variâncias entre canais dentro de cada bancada e entre bancadas não heterogêneas pelo teste de Bartlett.

entre os tipos de suporte. O pesquisador deverá optar entre precisão e número de tratamentos por bancada; por exemplo, usando lona plástica como suporte e um d igual a $10 \%$ poderão ser casualizados até $84 / 17$ igual a cinco tratamentos em cada bancada e, usando d igual a 5\% poderão ser usados apenas dois tratamentos por bancada.
Tabela 2 - Tamanho de amostra, numa população finita de 84 plantas, necessária para uma estimativa por intervalo a $95 \%$ de confiança para uma semi-amplitude de $5 \%$. $10 \%$ e $20 \%$ da média da massa fresca por planta de alface em hidroponia, para diferentes suportes. Santa Maria, 1998.

\begin{tabular}{lcccc}
\hline Suporte & Bancada & $5 \%$ & $10 \%$ & $20 \%$ \\
\hline Brita & 1 & 40 & 17 & 07 \\
Brita & 2 & 35 & 14 & 06 \\
Isopor & 1 & 46 & 20 & 08 \\
Isopor & 2 & 39 & 15 & 07 \\
Plástico & 1 & 40 & 17 & 07 \\
Plástico & 2 & 40 & 17 & 07 \\
& & & & \\
\hline
\end{tabular}

\section{CONCLUSÕES}

Usando uma estrutura de cultivo de alface em hidroponia sobre bancadas de fibrocimento com seis canais, o delineamento experimental adequado é o de blocos ao acaso se a unidade experimental for constituída de faixas transversais aos canais das bancadas e deve ser inteiramente casualizado se a bancada for a unidade experimental. Para a variável massa fresca de plantas, o tamanho da amostra é de 40 plantas para uma semi-amplitude do intervalo de confiança em percentagem da média (d) igual a $5 \%$ e de sete plantas para digual a $20 \%$.

\section{REFERÊNCIAS BIBLIOGRÁFICAS}

CASTEllane, P.D., ARAÚJO, J.A.C. Cultivo sem solo: Hidroponia. Jaboticabal : FUNEP, 1994. 43p.

LOPES, S.J., STORCK, L., HELDWEIN, A.B., et al. Técnicas experimentais para tomateiro tipo salada sob estufas plásticas. Ciência Rural, Santa Maria, v.28, n.2, p.193-197, 1998.

MIRANDA FILHO, J.B. Princípios de experimentação e análise estatística. In: PATERNIANI, E., VIEGAS, G.P. Melhoramento e produção do milho. 2 ed. Campinas : Fundação Cargill, 1987. v.2. p.765-795.

PEIRETTI, D.A., BIDERBOST, E.B., CARRERAS, J.J., et al. Tamaño y forma de la parcela experimental de ajo (Allium sativum L.). Revista de Ciências Agropecuárias, Córdoba, v.7, p.45-48, 1990.

PÉLLICO NETTO, S., BRENA, D.A. Inventário florestal. Curitiba : Universidade Federal do Paraná / Universidade Federal de Santa Maria, 1993. 245p.

PELLINCER, M.C., RINCON, L., SAEZ, J. Las soluciones nutritivas. Horto información, Madrid, v.3, p.39-43, 1995.

PENNINGSFELD, E., KURZMANN, P. Cultivos hydroponicos y en turba. Madrid : Mundi Prensa, 1983. 343p.

STEEL, R.G.D., TORRIE, J.H. Principles and procedures of statistics. New York : McGraw-Hill, 1960. 481p.

ZANON, M.L.B., STORCK, L., FINGER, C.A.G., et al. Tamanho de amostra para experimentos de Eucalyptus saligna Smith em viveiro. Ciência Florestal, Santa Maria, v.7, n.1, p.133-138, 1997. 